\title{
Role of the plant cell wall in gravity resistance
}

Takayuki Hoson, Kazuyuki Wakabayashi

\begin{tabular}{|c|l|}
\hline Citation & Phytochemistry. 112; 84-90 \\
\hline Issue Date & $2015-04$ \\
\hline Type & Journal Article \\
\hline Textversion & Author \\
\hline \multirow{2}{*}{ Rights } & $\begin{array}{l}\text { C } 2014 \text { Elsevier Ltd. This manuscript version is made available under the CC-BY-NC-ND } \\
\text { This is the accepted manuscript version. The article has been published in final form at } \\
\text { https://doi.org/10.1016/j.phytochem.2014.08.022. }\end{array}$ \\
\hline DOI & \begin{tabular}{l} 
10.1016/j.phytochem.2014.08.022 \\
\hline
\end{tabular} \\
\hline
\end{tabular}

\author{
Self-Archiving by Author(s) \\ Placed on: Osaka City University
}

HOSON, T., \& WAKABAYASHI, K. (2015). Role of the plant cell wall in gravity resistance.

Phytochemistry. 112, 84-90. doi:10.1016/j.phytochem.2014.08.022 


\title{
Role of the plant cell wall in gravity resistance
}

\author{
Takayuki Hoson*, Kazuyuki Wakabayashi
}

\author{
Department of Biology, Graduate School of Science, Osaka City University, Sumiyoshi-ku, Osaka \\ 558-8585, Japan \\ * Corresponding author at: Department of Biology, Graduate School of Science, Osaka City \\ University, Sumiyoshi-ku, Osaka 558-8585, Japan \\ Tel/fax: +8166605 2577 \\ E-mail address: hoson@sci.osaka-cu.ac.jp (T. Hoson).
}

\section{ABSTRACT}

Gravity resistance, mechanical resistance to the gravitational force, is a principal graviresponse in plants, comparable to gravitropism. The cell wall is responsible for the final step of gravity resistance. The gravity signal increases the rigidity of the cell wall via the accumulation of its constituents, polymerization of certain matrix polysaccharides due to the suppression of breakdown, stimulation of cross-link formation, and modifications to the wall environment, in a wide range of situations from microgravity in space to hypergravity. Plants thus develop a tough body to resist the gravitational force via an increase in cell wall rigidity and the modification of growth anisotropy. The development of gravity resistance mechanisms has played an important role in the acquisition of responses to various mechanical stresses and the evolution of land plants.

Keywords:

Cell wall / Cellulose / Evolution / Gravity resistance / Hypergravity / Matrix polysaccharides / Microgravity / Phenolics / Rigidity / Space experiments

\section{Abbreviations:}

DFA, diferulic acid; FA, ferulic acid; XTH, xyloglucan endo-transglucosylase/hydrolase 


\section{Introduction}

Plants are surrounded by a great variety of environmental signals to which they have developed efficient response systems during their evolution. Gravity is unique among the environmental signals important for plant life in that it is always present in a constant direction and magnitude on earth. Plants have utilized gravity as the most stable and reliable signal for their survival. Gravitropism is a typical graviresponse that enables plants to orient their leaves to sunlight and to develop a root system for anchoring and absorbing water and minerals.

To study gravitropism, mutants with impaired graviperception and signal transduction pathways have been isolated and effectively used for the characterization and understanding of these mechanisms (Tasaka et al., 2001; Morita, 2010; Baldwin et al., 2013; Blancaflor, 2013). Weeping, which is characterized by hanging branches and is most common in trees, is also caused by a genetic mutation. Branches of most weeping trees show normal gravitropism, but they are too soft to support their own weight (Nakamura et al., 1994). Weeping is not a mutant of gravitropism, but one where the plant loses the capacity to maintain enough mechanical rigidity to resist the gravitational force.

Plant stem organs, when turned on their sides, begin to bend upward and then continue to grow in the direction opposite to the pull of gravity. In the dark, the whole process has been ascribed to gravitropism. However, the initial curvature, true gravitropism, and the following straight growth against gravity are quite different in origin and mechanisms. Thus, mechanical resistance to the gravitational force may be a principal graviresponse in plants, independent of gravitropism. Nevertheless, the presence of this gravity response has not been properly recognized for long.

We have termed this response 'gravity resistance' and examined its nature and mechanism mainly by ground-based experiments using hypergravity conditions, produced by centrifugation, and by space experiments (Hoson and Soga, 2003; Hoson et al., 2005; Hoson et al., 2009). As a result, we have clarified the outline of the sequence of events in gravity resistance, and shown that gravity resistance is surely the major graviresponse in plants, distinct from gravitropism. In gravitropism, the gravity signal is perceived by the sedimentation of amyloplasts in statocytes. The perceived signal is then transformed by the relocalization of auxin efflux carriers and transmitted intercellularly to growing cells via the polar transport of auxin, and the resultant asymmetric distribution of auxin induces differential growth, leading to gravitropic curvatures (Tasaka et al., 2001; Morita, 2010; Blancaflor, 2013; Baldwin et al., 2013). On the other hand, in gravity resistance, the gravity signal may be perceived by mechanoreceptors (mechanosensitive ion channels) on the plasma membrane of not only statocytes but also other types of cells, and amyloplast sedimentation in statocytes is not directly involved (Soga et al., 2004, 2005). The perceived signal may be then transformed and transduced intracellularly within each cell, which may involve modulations of the expression of diverse genes, leading to modifications to the formation and functions of various cellular components. 
Plant cells are surrounded by well-developed cell walls, which are the major source of mechanical strength for plant bodies. The cell wall is also the site where the plant cell first meets a variety of environmental signals, and as such is the major location of plant responses to these signals (Hoson, 1998, 2002). Thus, the plant cell wall may be responsible for gravity resistance, like the bones and muscles in an animal body. We have obtained evidence supporting this hypothesis by extensive analyses of the changes in the mechanical and chemical properties of the cell wall in plant materials grown under different gravity conditions. In the preset article, we discuss, based on data obtained, the role of the cell wall in gravity resistance in plants.

\section{Cell wall changes under hypergravity conditions}

\subsection{Mechanical properties}

Removing the gravitational force and analyzing the changes induced can be effective for understanding the nature and mechanisms of gravity resistance. However, true microgravity produced by free fall or parabolic flight on earth lasts too briefly to induce obvious changes in plant growth or cell wall properties. Therefore, basipetal hypergravity produced by centrifugation has mainly been used for the analysis of gravity resistance (Hoson and Soga, 2003; Hoson et al., 2005), the same as for gravitropism (Hodick and Sievers, 1998; Fitzelle and Kiss, 2001). Hypergravity generally suppresses elongation growth but promotes the lateral expansion of plant organs (Soga et al., 2006; Allen et al., 2009). The effects of hypergravity on the mechanical properties of the cell wall have been analyzed in the stem organs and roots of various plant materials. The data have shown that hypergravity increases cell wall rigidity (Hoson and Soga, 2003; Hoson et al., 2005).

Plant organs are highly resistant to the gravitational force, and hypergravity at $30 \mathrm{~g}$ and above is required to induce significant changes in the mechanical properties of the cell wall (Hoson and Soga, 2003). Cell wall rigidity varied in proportion to the logarithm of the magnitude of the gravitational force up to $300 \mathrm{~g}$. When plant seedlings grown under hypergravity at $300 \mathrm{~g}$ for several hours were transferred to $1 \mathrm{~g}$ conditions, cell wall rigidity recovered fully within a couple of hours, indicating that the effects of the gravitational force on the cell wall mechanical properties are prompt and reversible. In addition, horizontal and acropetal hypergravity increased cell wall rigidity, as did basipetal hypergravity. 


\subsection{Cellulose}

The mechanical properties of the cell wall are determined by the chemical nature of cell wall constituents and the interactions among them. The levels and the molecular size of cell wall constituents are important for the regulation of cell wall rigidity. The effects of hypergravity on the levels of cell wall polysaccharides were examined along azuki bean epicotyls (Nakano et al., 2007; Wakabayashi et al., 2009). Cellulose microfibrils in general play an important role in determining cell wall rigidity. The levels of cellulose gradually increased from the apical to the basal regions. Hypergravity increased the levels in the basal regions, but not in the upper growing regions, suggesting that cellulose acts as an anti-gravitational polysaccharide only in the supporting regions of seedlings. Cellulose accumulation was also induced by hypergravity in pollen tubes (Chebli et al., 2013). Cellulose is synthesized on the plasma membrane by cellulose synthase complexes. It has been reported that the expression of cellulose synthase genes is upregulated by hypergravity (Martzivanou and Hampp, 2003; Tamaoki et al., 2009). The contribution of the up-regulation of cellulose synthase genes to cellulose accumulation in gravity resistance remains to be evaluated by further studies.

Not only the levels but also the orientation of cellulose microfibrils influence the mechanical properties of the cell wall. The co-alignment hypothesis states that the movement of cellulose synthase complexes on the plasma membrane is constrained by interactions with cortical microtubules. It is likely that cellulose microfibrils and cortical microtubules are mutually dependent in their functions in gravity resistance. The expression of most $\alpha$ - and $\beta$-tubulin genes was upregulated by hypergravity in Arabidopsis hypocotyls, depending on the magnitude of the gravitational force (Yoshioka et al., 2003; Matsumoto et al., 2007). In the epidermis of azuki bean epicotyls grown at $1 g$, cells with transverse cortical microtubules were predominant. With increasing gravitational force, the percentage of cells with transverse microtubules decreased, but the percentage with longitudinal microtubules increased (Soga et al., 2006). The reorientation of cortical microtubules occurred promptly after the transfer of seedlings from $1 g$ to hypergravity conditions. Hypergravity also transiently increased the expression of $\gamma$-tubulin and katanin genes (Soga et al., 2008, 2009), which are assumed to be responsible for the reorientation of cortical microtubules (Murata et al., 2005). On the other hand, the hypocotyls of Arabidopsis tubulin mutants were shorter and thicker than those of the wild-type, and showed either left-handed or right-handed helical growth at $1 \mathrm{~g}$. The degree of the twisting phenotype was intensified under hypergravity conditions (Matsumoto et al., 2010). These results indicate that cortical microtubules are involved in gravity resistance by sustaining the function of cellulose microfibrils.

Angiosperm trees form tension wood, consisting mainly of cellulose microfibrils parallel to the long cell axis, on the upper side of leaning stems to increase the mechanical support when exposed to a gravitational stimulus. For details on the role of cellulose in the resistance of tree branches to the gravitational force, see Timell (1986), Archer (1987), Du and Yamamoto (2007), and Hoson (2010). 


\subsection{Matrix polysaccharides}

The levels of matrix (non-cellulosic) polysaccharides were almost constant over the regions in azuki bean epicotyls. The matrix levels were increased by hypergravity in the upper growing regions, but not in the basal regions (Nakano et al., 2007; Wakabayashi et al., 2009). Hypergravity in general has been shown to increase cell wall thickness, but no clear differences were detected in the proportions of cell wall polysaccharides in the growing regions between control and hypergravity-treated seedlings (Hoson and Soga, 2003; Hoson et al., 2005). On the other hand, hypergravity caused the polymerization of certain matrix polysaccharides, the types of which differed between dicotyledonous plants and monocotyledonous Gramineae plants. In dicotyledons, hypergravity increased the molecular mass of xyloglucans, whereas hypergravity increased that of $1,3,1,4-\beta$-glucans in Gramineae plants. Hypergravity also decreased the xyloglucan-degrading activity in dicotyledons and 1,3,1,4- $\beta$-glucanase activity in Gramineae. In addition, modifications to xyloglucan metabolism under hypergravity conditions were regulated by prompt and differential changes in the expression of xyloglucan endo-transglucosylase/hydrolase $(X T H)$ genes (Soga et al., 2007). Out of three major $X T H$ genes, the expression of only one gene, which is devoted to xyloglucan breakdown (Tabuchi et al., 2001), was specifically down-regulated by hypergravity, suggesting that xyloglucan metabolism is regulated at the transcriptional level. In pollen tubes, hypergravity altered intracellular vesicle transport related to the synthesis of matrix polysaccharides (Chebli et al., 2013). Thus, modification to the metabolic turnover of matrix polysaccharides as well as their accumulation may be involved in making the cell wall mechanically rigid to resist the gravitational force under hypergravity conditions. Xyloglucans and 1,3,1,4- $\beta$-glucans may play a principal role as anti-gravitational polysaccharides, particularly in the growing regions of stem organs.

\subsection{Phenolics}

Certain differentiated cell walls of terrestrial plants contain a significant amount of phenolic substances such as lignin. Lignin is a complex phenolic polymer with high molecular mass and is formed by the polymerization of hydroxycinnamyl monomers on a polysaccharide network. Lignin forms a complex net of cross-links among cell wall constituents and cements them in place. Therefore, the formation of lignin may contribute to increasing cell wall rigidity and to keeping cell wall architecture. The lignin content in garden cress hypocotyls increased in response to hypergravity treatment (Hoson et al., 1996). In the inflorescence stems of Arabidopsis that had been subjected to hypergravity for 1 day and subsequently grown for another 3 days at $1 g$, the lignin content was 
higher than in those grown under continuous $1 \mathrm{~g}$ conditions, in particular in the basal regions (Tamaoki et al., 2006). In addition, the lignin content increased gradually from the apical to the basal regions of azuki bean epicotyls, and hypergravity treatment for $6 \mathrm{~h}$ stimulated the increase in the content, particularly in the middle and basal regions (Wakabayashi et al., 2009). These results indicate that the promotion of lignin formation occurs promptly after the onset of hypergravity stimuli and that the increase in lignin content in the basal regions of stem organs may help support the aerial parts of the plant body against the increased gravitational force.

The polymerization of lignin is catalyzed by cell wall-bound peroxidase. The peroxidase activity in the cell wall of azuki bean epicotyls increased gradually toward the basal region, and hypergravity treatment increased peroxidase activity, particularly in the middle and basal regions (Wakabayashi et al., 2009). Martzivanou and Hampp (2003) reported that hypergravity increased the transcription level of lignification-related peroxidase in callus cultures of Arabidopsis. Furthermore, hypergravity treatment upregulated the expression of genes responsible for lignin formation, including peroxidase (ATPA2), in Arabidopsis inflorescence stems (Tamaoki et al., 2009, 2011). These findings suggest that hypergravity primarily stimulates the expression of peroxidase genes and that the resultant increase in peroxidase activity may be involved in the promotion of lignin formation in stem organs.

In addition to lignin, the cell walls of gramineous plants contain a significant amount of hydroxycinnamate monomers, such as feruric acid (FA) and p-coumaric acid, which are ester-bound to the arabinose residues of arabinoxylans. Of these hydroxycinnamates, some FAs undergo a peroxidase-catalyzed coupling reaction to produce diferulic acid (DFA) and ferulate oligomers, which may cross-link arabinoxylans (Fry, 1986; Bunzel, 2010). The formation of such cross-linkages creates a rigid network within the cell wall architecture (Fry, 1986; Carpita and Gibeaut, 1993). Continuous hypergravity treatment increased FA and DFA content in the cell walls of wheat shoots (Wakabayashi et al., 2005a, 2005b). In particular, the amount of DFA substantially increased in response to prolonged hypergravity treatment (Wakabayashi et al., 2005a), indicating that hypergravity increases the DFA-mediated cross-links within cell wall architecture. The stimulation of DFA formation under hypergravity conditions may increase cell wall rigidity and thus enhance resistance to the gravitational force.

DFA is synthesized by the coupling reaction of FA residues, and cell wall-bound peroxidases have been thought to catalyze the reaction. The activity of cell wall-bound peroxidase substantially increased during the growth of rice shoots and there was a close correlation between the DFA content and the enzyme activity (Wakabayashi et al., 2012). The ratio of DFA to FA in cell walls of wheat shoots largely increased under continuous hypergravity conditions (Wakabayashi et al., 2005a), suggesting that hypergravity stimulates the coupling reaction of FA. Since hypergravity increased the activity of cell wall-bound peroxidase as described above, such an increase may be involved in the stimulation of DFA formation even in gramineous shoots. 


\subsection{Cell wall environment}

The activity of cell wall enzymes that are responsible for the metabolism of cell wall constituents is determined in situ not only by their protein levels but also by the cell wall environment. Out of the various factors of the cell wall environment, the apoplastic $\mathrm{pH}$ is the most important for regulating the activity of cell wall enzymes in situ (Bolwell et al., 2002; Hoson, 2002; Cosgrove, 2005). Hypergravity has been shown to increase the apoplastic $\mathrm{pH}$ of various materials (Soga et al., 2000a, 2000b). Because vanadate, an inhibitor of P-type ATPase, also increased the apoplastic $\mathrm{pH}$ and because hypergravity had no further effects on the $\mathrm{pH}$ in the presence of vanadate, hypergravity may increase the apoplastic $\mathrm{pH}$ via the reduction of the activity of the plasma membrane $\mathrm{H}^{+}$-ATPase (proton pump). When the activities of xyloglucan and 1,3,1,4- $\beta$-glucan degradation were assayed at the $\mathrm{pH}$ corresponding to the $\mathrm{pH}$ value of the hypergravity-treated cell wall, a significant decrease in activity was detected (Soga et al., 2000a, 2000b). Thus, the gravity signal may modify the metabolism of cell wall constituents not only directly but also via regulation of the cell wall environment when it increases cell wall rigidity. The changes in cytoplasmic and wall $\mathrm{pH}$ are also involved in the initial events of gravity perception or signal transduction in the gravitropism of roots (Fasano et al., 2001).

\section{Cell wall changes under submergence}

It is difficult to eliminate the effects of the gravitational force for long enough on earth, as mentioned above. Water immersion has been used as a simulator of microgravity in the space sciences and technologies. Land plants, in general, are not able to survive underwater. However, aquatic or semi-aquatic plants such as rice can grow for a long period under conditions of submergence.

Rice coleoptiles elongate rapidly and are slender when growing underwater. When rice coleoptiles are exposed to the air, namely to $1 \mathrm{~g}$ gravity, they become short and thick. One major factor inducing such a difference in the growth pattern may be buoyancy. Thus, the morphological change in the air is recognized as the response of plant seedlings to resist the gravitational force. Also, the change in growth conditions from underwater to in the air appears to be similar to what plant ancestors experienced when they first grew on land about 450 million years ago (Hoson, 2006).

The cell wall rigidity of rice coleoptiles when grown under submergence is lower than when grown in the air (Hoson, 1998; Hoson and Soga, 2003). Submergence also causes diverse changes in the levels and metabolism of the cell wall constituents of rice coleoptiles. The levels of cellulose and 
matrix polysaccharides per unit length in rice coleoptiles grown under submergence were significantly lower than those grown in the air (Tan et al., 1991; Masuda et al., 1994). The rate of accumulation of both polysaccharides decreased when rice coleoptiles grown in the air were submerged (Kutschera et al., 1993; Kawamura et al., 2000). The sugar composition and the molecular mass of matrix polysaccharides such as 1,3,1,4- $\beta$-glucans in coleoptiles grown under submergence were also different from those grown in the air (Revilla and Zarra, 1987; Masuda et al., 1994). Both the level of 1,3,1,4- $\beta$-glucans and the activity of $1,3,1,4-\beta$-glucanases were higher in coleoptiles grown under submergence than in those grown in the air (Chen et al., 1999). Significant differences were also detected in the levels of cell wall-bound monophenols. Rice coleoptiles grown under submergence contained lower levels of FA and DFA ester-linked to matrix polysaccharides than those grown in the air (Tan et al., 1991) and their levels in the coleoptiles grown in the air were decreased by submergence (Kutschera et al., 1993; Kawamura et al., 2000). Similar changes in growth and cell wall properties have also been observed in deepwater rice (Kutschera and Kende, 1988) and some other aquatic plants such as Regnillidium (Jackson, 1985). Thus, the modifications to growth and the cell wall properties of plant seedlings brought about under submergence are the opposite of those caused by hypergravity.

\section{Cell wall changes under microgravity conditions in space}

\subsection{Mechanical properties}

Studies on cell wall changes under true microgravity in space have been limited to fragmental analyses of the levels and organization of cellulose and lignin, without any report on the effects of microgravity on the mechanical properties (Hoson and Soga, 2003; Hoson et al., 2005; Hoson et al., 2009). We have analyzed both the mechanical and chemical properties of the cell wall of space-grown seedlings under conditions where environmental factors other than gravity, such as temperature, light, water, and gas composition, were strictly regulated (Hoson et al., 2002; Soga et al., 2002). The elongation growth of both Arabidopsis hypocotyls (Soga et al., 2002; Matia et al., 2010) and rice coleoptiles (Hoson et al., 2002) was stimulated in space. The cell wall rigidity of both organs increased as the growth period increased and was always lower in space-grown seedlings than in the controls.

In the recent Space Seed experiment on the Kibo Module on board the International Space Station, we cultivated Arabidopsis plants for 33 days and analyzed the growth and cell wall mechanical properties of their inflorescences (Hoson et al., 2014). The growth of inflorescence stems 
was stimulated under microgravity conditions in space as compared with ground and on-orbit $1 g$ conditions. The cell wall rigidity in apical elongating regions of inflorescences was significantly lower under microgravity conditions than ground and on-orbit controls. No clear differences were detected in the cell wall mechanical properties between both controls, indicating that the decrease in cell wall rigidity was induced by microgravity, not by space flight.

\subsection{Cellulose}

As to the chemical nature of the cell wall constituents, the space-grown rice coleoptiles and Arabidopsis hypocotyls had lower levels of cellulose and matrix polysaccharides per unit length than the controls, indicating that microgravity decreased the cell wall thickness (Hoson et al., 2002; Soga et al., 2002). However, no clear differences were detected in the proportions of wall polysaccharides between control and space-grown seedlings. The effect of microgravity on the level of cell wall polysaccharides such as cellulose should be clarified by future space experiments.

It has been suggested that cortical microtubules play an important role in plant resistance to hypergravity, as mentioned above. However, it is uncertain whether the hypothesis is applicable to the gravity resistance of plants under $1 g$ gravity. To clarify this point, we are conducting a series of space experiments, Space Seed, Resist Tubule, and Aniso Tubule, on the Kibo Module of the International Space Station (Hoson et al., 2012, 2014). There are two major objectives in these experiments. One is to analyze the modifications to the dynamics of cortical microtubules under microgravity conditions on-site using GFP-expressing Arabidopsis lines. The other is to quantify the contributions of cortical microtubules to gravity resistance using tubulin mutants with different degrees of defects. We have shown that the growth of inflorescence stems of one tubulin mutant, tua6, was restored under microgravity conditions in space, where gravity resistance is not required and the defects of mutants are not disadvantageous for their growth (Hoson et al., 2014), but the quantitative relation has not been clarified yet. We expect that these space experiments will greatly contribute to our understanding of the mechanism of gravity resistance in plants.

\subsection{Matrix polysaccharides}

The space-grown rice coleoptiles and Arabidopsis hypocotyls also had a lower molecular mass of the matrix polysaccharides, which is mainly due to the decrease in the molecular size of 1,3,1,4- $\beta$-glucans in rice and xyloglucans in Arabidopsis (Hoson et al., 2002; Soga et al., 2002). In 
Arabidopsis hypocotyls, the activity of xyloglucan-degrading enzymes was increased in space, suggesting that microgravity reduces the molecular mass of xyloglucans by stimulating their breakdown (Soga et al., 2002). These changes in cell wall properties are similar to those observed in rice coleoptiles grown under submergence, but opposite to those induced by hypergravity. These results support the hypothesis that under microgravity in space the metabolic turnover of cell wall constituents of plant seedlings is activated, which leads to a decrease in cell wall rigidity.

In space, the elongation growth of rice roots was also stimulated (Hoson et al., 2003). However, the cell wall rigidity per unit cross-sectional area of space-grown roots was not lower, but somewhat higher than the control, and a corresponding increase in the molecular size of the matrix polysaccharides was observed. On the other hand, the levels of both cellulose and matrix polysaccharides per unit length of roots decreased greatly. The prominent thinning of the cell wall may overwhelm the disadvantageous changes in the cell wall mechanical properties, leading to the stimulation of elongation growth in rice roots in space. The cell wall properties of roots are in general regulated not only by the gravitational force but also by other factors such as soil water content and physical contact with the soil or medium components.

\subsection{Phenolics}

The changes in lignin content and formation under microgravity conditions have been examined in some space experiments. However, the results are controversial. Pine and mung bean seedlings were exposed for 8 days to a microgravity environment on board the space shuttle (Cowles et al., 1989). The lignin contents in space-grown pine hypocotyls and mung bean hypocotyls and epicotyls were lower than in those grown at $1 g$ on earth. Furthermore, peroxidase activity in space-grown pine hypocotyls was lower than that of ground controls (Cowles et al., 1989). On the other hand, Levine et al. (2001) reported that there were no significant differences in lignin content between wheat seedlings grown in space and on earth. Similarly, the lignin content in wheat leaves that had been grown for three weeks under microgravity conditions in space was almost comparable to that in wheat grown on earth (Stutte et al., 2006). Such a discrepancy may be derived from different cultivation conditions, such as light intensity, water and gas environments, and temperature, as well as different life stages of plant materials, and remains to be clarified.

On the other hand, the effects of microgravity on the formation of hydroxycinnamates in gramineous plants have not been investigated yet. We have just conducted the space experiment termed Ferulate, in which the levels of cell wall phenolic components including FA and DFA in rice seedlings were examined under microgravity conditions in space. Details are now under investigation. 


\section{Concluding Remarks}

Hypergravity has been shown to increase the cell wall rigidity in various stem organs and roots. However, the cell wall rigidity of plants grown under microgravity conditions in space was lower than that of the controls. As to the chemical nature of cell wall constituents, hypergravity increased cell wall thickness in plant materials. Hypergravity also caused the polymerization of certain matrix polysaccharides, xyloglucans in dicotyledons and 1,3,1,4- $\beta$-glucans in Gramineae. A decrease in the activities of xyloglucan and 1,3,1,4- $\beta$-glucan degradation, and the down-regulation of the expression of genes responsible for such degradation, were brought about by hypergravity. On the other hand, cell wall thickness was decreased under microgravity conditions in space. The space-grown plants also contained xyloglucans and 1,3,1,4- $\beta$-glucans with lower molecular masses, resulting from the increases in xyloglucan-degrading and 1,3,1,4- $\beta$-glucanase activities. In addition, the levels of phenolics such as lignin and DFA were increased by hypergravity, but tended to be decreased under microgravity conditions. These results indicate that plants increase the rigidity of their cell walls via modifications to the metabolism of cell wall constituents in the final step of gravity resistance. The increase in cell wall rigidity by the gravitational force was usually accompanied by the suppression of elongation growth and stimulation of lateral expansion. The parameters on growth and cell wall properties varied in proportion to the logarithm of the magnitude of gravity in the range from microgravity to hypergravity. Taken together, it is concluded that plants resist the gravitational force by developing a tough body via an increase in cell wall rigidity and the modification of growth anisotropy.

Figure 1 summarizes the sequence of events leading to gravity resistance in plants. The gravity signal may be perceived by mechanoreceptors located on the plasma membrane. The perceived signal may be transformed and transduced via the structural continuum or physiological continuity of cortical microtubules and the plasma membrane, and then induce the expression of diverse genes and influence the formation and structure of various cellular components. By these steps, the metabolism of cell wall constituents, such as cellulose, matrix polysaccharides, and phenolics, is regulated. At the same time, transformed signals may be transduced through the plasma membrane and modify the activities of proton pumps or other ion channels. In this way, the cell wall environment is regulated. In addition, the changes in the orientation of cortical microtubules may bring about modifications of cellulose orientation. Modifications to the cell wall environment, in combination with changes in the metabolism of cell wall constituents, determine cell wall rigidity, leading to gravity resistance. 


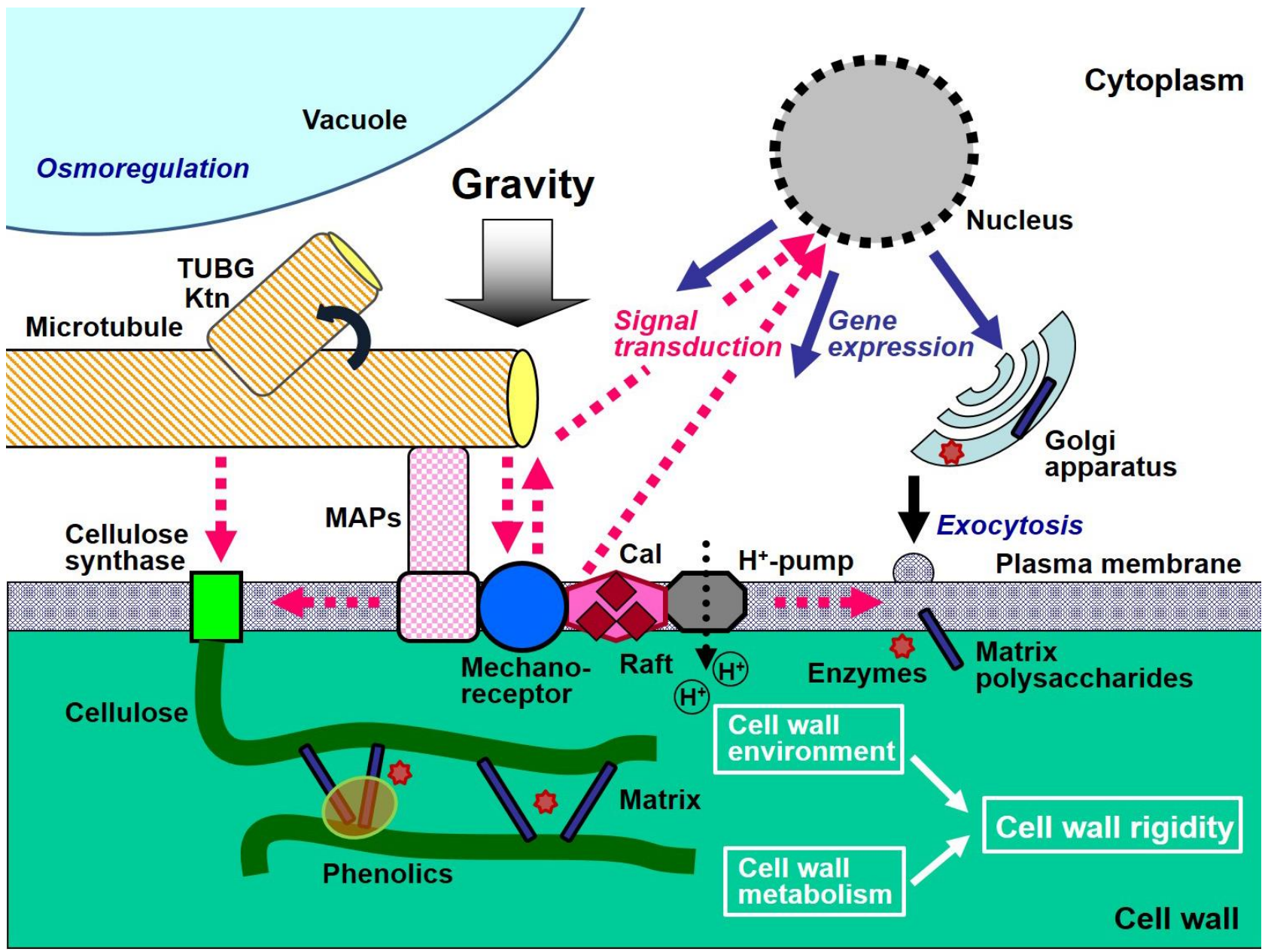

Fig. 1. Mechanisms of signal perception, transduction, and response in gravity resistance.

Gravity is the most stable signal on earth. At the same time, plants have been exposed to a variety of mechanical stresses such as wind on land. As described above, the gravity signal may be perceived by mechanoreceptors on the plasma membrane in gravity resistance. The mechanoreceptors are also assumed to be involved in the perception of mechanical stress signals (Braam, 2005; Hoson, 2010). In addition, cell wall hardening is generally induced in response to mechanical stimuli (Braam, 2005; Hoson, 2010; Verhertbruggen et al., 2013), the same as for the gravity signal. Thus, gravity may share the common pathway of signal perception, transduction, and response at least in part with mechanical stresses. The development of the mechanisms of gravity resistance should be important for the acquisition of responses to mechanical stresses for plants.

When plant ancestors appeared in the sea, their bodies were surrounded by soft cell coverings because the magnitude of the gravitational force actually applied to them was lower underwater due to buoyancy, and thus it was not necessary for them to develop hard bodies. After plants first emerged on land, probably about 450 million years ago in the mid-Ordovician, they were directly exposed to a gravitational force of $1 \mathrm{~g}$. Only plants that successfully evolved a tough body with rigid 
cell walls were able to resist the force and survive on land (Hoson, 2006; Volkmann and Baluška, 2006). The pectin network may be the most ancient type of rigid cell wall and this may have been reinforced first by the cellulosic network and later also by lignins (Volkmann and Baluška, 2006). The development of the mechanisms of gravity resistance was indispensable for the transition of plant ancestors from an aquatic environment to a terrestrial environment and the consequent establishment of land plants. In addition, the evolution of land plants was a prerequisite for the life of all terrestrial organisms, including us, because all organisms fully depend on plants for nutrients and habitable environments. Thus, plant cell walls have played a principal role in the evolution of life on earth. In other words, gravity has acted as the driving force of the evolution of life via stimulating the development of rigid cell walls in plants.

Plants have developed rigid cell walls to resist the gravitational force, as mentioned above. The cell wall often accounts for more than $90 \%$ of their dry matter and energy consumption, particularly in tall trees, and appears to be greater than what is actually needed for the purpose. Thus, the cell wall is a valuable target for biotechnological applications. The effectiveness of the bioengineering of the cell wall has been discussed (Grabber, et al., 2010; Yoshida, et al., 2013; Slavov, et al., 2014). Studying the mechanism underlying gravity resistance may greatly contribute to advances in cell wall bioengineering, leading to a more efficient utilization of plant materials.

\section{Acknowledgements}

The ground-based studies and space experiments by the authors mentioned in the present article were supported by the Japan Aerospace Exploration Agency, Japan Space Forum, and Grants-in-Aid for Scientific Research from the Japan Society for the Promotion of Science. 


\section{References}

Allen, J., Bisbee, P.A., Darnell, R.L., Kuang, A., Levine, L.H., Musgrave, M.E., van Loon, J.J., 2009. Gravity control of growth form in Brassica rapa and Arabidopsis thaliana (Brassicaceae): Consequences for secondary metabolism. Am. J. Bot. 96, 652-660.

Archer, R.R., 1987. Growth Stresses and Strains in Trees, Springer-Verlag, Berlin.

Baldwin, K.L., Strohm, A.K., Masson, P.H., 2013. Gravity sensing and signal transduction in vascular plant primary roots. Am. J. Bot. 100, 126-142.

Blancaflor, E.B., 2013. Regulation of plant gravity sensing and signaling by the actin cytoskeleton. Am. J. Bot. 100, 143-152.

Bolwell, G.P., Bindschedler, L.V., Blee, K.A., Butt, V.S., Davies, D.R., Gardner, S.L., Gerrish, C., Minibayeva, F., 2002. The apoplastic oxidative burst in response to biotic stress in plants: a three-component system. J. Expt. Bot. 53, 1367-1376.

Braam, J., 2005. In touch: plant responses to mechanical stimuli. New Phytol. 165, 373-389.

Bunzel, M., 2010. Chemistry and occurrence of hydroxycinnamate oligomers. Phytochem. Rev. 9, 47-64.

Carpita, N.C., Gibeaut, D.M., 1993. Structural model of the primary cell walls in flowering plants: consistency of molecular structure with the physical properties of the walls during growth. Plant J. 3, $1-30$.

Chebli, Y., Pujol, L., Shojaeifard, A., Brouwer, I., van Loon, J.J., Geitmann, A., 2013. Cell wall assembly and intracellular trafficking in plant cells are directly affected by changes in the magnitude of gravitational acceleration. PLoS One 8, e58246.

Chen, L., Kamisaka, S., Hoson, T., 1999. Breakdown of $(1 \rightarrow 3),(1 \rightarrow 4)-\beta$-D-glucans during development of rice coleoptiles in air and under water. J. Plant Physiol. 155, 234-239. Cosgrove, D.J., 2005. Growth of the plant cell wall. Nat. Rev. Mol. Cell Biol. 6, 850-861.

Cowles, J.R., LeMay, R., Jahns, G., Scheld, W.H., Peterson, C., 1989. Lignification in young plant seedlings grown on earth and aboard the space shuttle. In: Lewis, N.G., Paice, M.G. (Eds), Plant Cell 
Wall Polymers. Biogenesis and Biodegradation. ACS Symposium Series 399. American Chemical Society, Washington DC, pp. 203-213.

Du, S., Yamamoto, F., 2007. An overview of the biology of reaction wood formation. J. Int. Plant Biol. 49, 131-143.

Fitzelle, K.J., Kiss, J.Z., 2001. Restoration of gravitropic sensitivity in starch-deficient mutants of Arabidopsis by hypergravity. J. Exp. Bot. 52, 265-275.

Fry, S.C., 1986. Cross-linking of matrix polymers in the growing cell walls of angiosperms. Annu. Rev. Plant Physiol. 37, 165-186.

Fasano, J.M., Swanson, S.J., Blancaflor, E.B., Dowd, P.E., Kao, T.H., Gilroy, S., 2001. Changes in root cap pH are required for the gravity response of the Arabidopsis root. Plant Cell 13, 907-921.

Grabber, J.H., Schatz, P.F., Kim, H., Lu, F., Ralph, J., 2010. Identifying new lignin bioengineering targets: 1. Monolignol-substitute impacts on lignin formation and cell wall fermentability. BMC Plant Biol. 10, 114.

Hodick, D., Sievers, A., 1998. Hypergravity can reduce but not enhance the gravitropic response of Chara globularis protonemata. Protoplasma 204, 145-154.

Hoson, T., 1998. Apoplast as the site of response to environmental signals. J. Plant Res. 111, 167-177.

Hoson, T., 2002. Physiological functions of plant cell coverings. J. Plant Res. 115, 277-282.

Hoson, T., 2006. The mechanism and significance of gravity resistance in plants. J. Gravit. Physiol. $13,97-100$.

Hoson, T., 2010. Cellulose as the anti-gravitational polysaccharide. In: Lejeune, A., Deprez, T. (Eds), Cellulose: Structure and Properties, Derivatives and Industrial Uses. Nova Science Publishers, New York, pp. 293-307.

Hoson, T., Soga, K., 2003. New aspects of gravity responses in plant cells. Int. Rev. Cytol. 229, 209-244. 
Hoson, T., Akamatsu, H., Soga, K., Wakabayashi, K., Hashimoto, H., Yamashita, M., Hasegawa, K., Yano, S., Omori, K., Ishioka, N., Matsumoto, S., Kasahara, H., Shimazu, T., Baba, S.A., Hashimoto, T., 2012. Objectives, outlines, and preparation for the Resist Tubule space experiment to understand the mechanism of gravity resistance in plants. Aerospace Technol. Japan 10, Tp 1-5.

Hoson, T., Nishitani, K., Miyamoto, K., Ueda, J., Kamisaka, S., Yamamoto, R., Masuda, Y., 1996. Effects of hypergravity on growth and cell wall properties of cress hypocotyls. J. Exp. Bot. 47, 513-517.

Hoson, T., Saito, Y., Soga, K., Wakabayashi, K., 2005. Signal perception, transduction, and response in gravity resistance. Another graviresponse in plants. Adv. Space Res. 36, 1196-1202.

Hoson, T., Soga, K., Mori, R., Saiki, M., Nakamura, Y., Wakabayashi, K., Kamisaka, S., 2002. Stimulation of elongation growth and cell wall loosening in rice coleoptiles under microgravity conditions in space. Plant Cell Physiol. 43, 1067-1071.

Hoson, T., Soga, K., Wakabayashi, K., 2009. Role of the cell wall-sustaining system in gravity resistance in plants. Biol. Sci. Space 23, 131-136.

Hoson, T., Soga, K., Wakabayashi, K., Hashimoto, T., Karahara, I., Yano, S., Tanigaki, F., Shimazu, T., Kasahara, H., Masuda, D., Kamisaka, S., 2014. Growth stimulation in inflorescences of an Arabidopsis tubulin mutant under microgravity conditions in space. Plant Biol. 16 (S1) 91-96.

Hoson, T., Soga, K., Wakabayashi, K., Kamisaka, S., Tanimoto, E., 2003. Growth and cell wall changes in rice roots during spaceflight. Plant Soil 255, 19-26.

Jackson, M.B., 1985. Ethylene and responses of plants to soil waterlogging and submergence. Annu. Rev. Plant Physiol. 36, 145-174.

Kawamura, Y., Wakabayashi, K., Hoson, T., Yamamoto, R., Kamisaka, S., 2000. Stress-relaxation analysis of submerged and air-grown rice coleoptiles: Correlations with cell wall biosynthesis and growth. J. Plant Physiol. 156, 689-694.

Kutschera, U., Kende, H., 1988. The biophysical basis of elongation growth in internodes of deepwater rice. Plant Physiol. 88, 361-366.

Kutschera, U., Hoss, R., Frohlich, M., Hoson, T., 1993. Analysis of the growth response of air-grown rice coleoptiles to submergence. Bot. Acta 106, 164-169. 
Levine, L.H., Heyenga, A.G., Levine, H.G., Choi, J.-W., Davin, L.B., Krikorian, A.D., Lewis, N.G., 2001. Cell-wall architecture and lignin composition of wheat developed in a microgravity environment. Phytochemistry 57, 835-846.

Martzivanou, M., Hampp, R., 2003. Hyper-gravity effects on the Arabidopsis transcriptome. Physiol. Plant. 118, 221-231.

Masuda, Y., Kamisaka, S., Yamamoto, R., Hoson, T., Nishitani, K., 1994. Plant responses to simulated microgravity. Adv. Space Biol. Med. 4, 111-126.

Matía, I., González-Camacho, F., Herranz, R., Kiss, J.Z., Gasset, G., van Loon, J.J., Marco, R., Medina, F.J., 2010. Plant cell proliferation and growth are altered by microgravity conditions in spaceflight. J. Plant Physiol. 167, 184-193.

Matsumoto, S., Kumasaki, S., Soga, K., Wakabayashi, K., Hashimoto, T., Hoson, T., 2010. Gravity-induced modifications to development in hypocotyls of Arabidopsis tubulin mutants. Plant Physiol. 152, 918-926.

Matsumoto, S., Saito, Y., Kumasaki, S., Soga, K., Wakabayashi, K., Hoson, T., 2007. Up-regulation of tubulin genes and roles of microtubules in hypergravity-induced growth modifications in Arabidopsis hypocotyls. Adv. Space Res. 39, 1176-1181.

Morita, M.T., 2010, Directional gravity sensing in gravitropism. Annu. Rev. Plant Biol. 61, 705-720.

Murata, T., Sonobe, S., Baskin, T.I., Hyodo, S., Hasezawa, S., Nagata, T., Horio, T., Hasebe, M., 2005. Microtubule-dependent microtubule nucleation based on recruitment of $\gamma$-tubulin in higher plants. Nat. Cell Biol. 10, 961-968.

Nakamura, T., Saotome, M., Ishiguro, Y., Itoh, R., Higurashi, S., Hosono, M., Ishii, Y., 1994. The effects of $\mathrm{GA}_{3}$ on weeping of growing choots of the Japanese cherry, Prunus spachiana. Plant Cell Physiol. 35, 523-527.

Nakano, S., Soga, K., Wakabayashi, K., Hoson, T., 2007. Different cell wall polysaccharides are responsible for gravity resistance in the upper and the basal regions of azuki bean epicotyls. Biol. Sci. Space 21, 113-116.

Revilla,G,. Zarra, I., 1987. Changes in the molecular weight distribution of the hemicellulosic 
polysaccharides from rice coleoptiles growing under different conditions. J. Expt. Bot. 38, 1818-1825.

Slavov, G.T., Nipper, R., Robson, P., Farrar, K., Allison, G.G., Bosch, M., Clifton-Brown, J.C., Donnison, I.S., Jensen, E., 2014. Genome-wide association studies and prediction of 17 traits related to phenology, biomass and cell wall composition in the energy grass Miscanthus sinensis. New Phytol. 201, 1227-1239.

Soga, K., Kotake, T., Wakabayashi, K., Kamisaka, S., Hoson, T., 2008. Transient increase in the transcript levels of $\gamma$-tubulin complex genes during reorientation of cortical microtubules by gravity in azuki bean (Vigna angularis) epicotyls. J. Plant Res. 121, 493-498.

Soga, K., Kotake, T., Wakabayashi, K., Kamisaka, S., Hoson, T., 2009. The transcript level of katanin gene is increased transiently in response to changes in gravitational conditions in azuki bean epicotyls. Biol. Sci. Space 23, 3-8.

Soga, K., Wakabayashi, K., Hoson, T., Kamisaka, S., 2000a. Changes in the apoplastic pH are involved in regulation of xyloglucan breakdown of azuki bean epicotyls under hypergravity conditions. Plant Cell Physiol. 41, 509-514.

Soga, K., Wakabayashi, K., Hoson, T., Kamisaka, S., 2000b. Hypergravity-induced increase in the apoplastic $\mathrm{pH}$ and its possible involvement in suppression of $\beta$-glucan breakdown in maize seedlings. Aust. J. Plant Physiol. 27, 967-972.

Soga, K., Wakabayashi, K., Kamisaka, S., Hoson, T., 2002. Stimulation of elongation growth and xyloglucan breakdown in Arabidopsis hypocotyls under microgravity conditions in space. Planta 215, 1040-1046.

Soga K., Wakabayashi K., Kamisaka S., Hoson, T., 2004. Graviperception in growth inhibition of plant shoots under hypergravity conditions produced by centrifugation is independent of that in gravitropism and may involve mechanoreceptors. Planta 218, 1054-1061.

Soga K., Wakabayashi K., Kamisaka S., Hoson T., 2005. Mechanoreceptors rather than sedimentable amyloplasts perceive the gravity signal in hypergravity-induced inhibition of root growth in azuki bean. Funct. Plant Biol. 32, 175-179. 
Soga, K., Wakabayashi, K., Kamisaka, S., Hoson, T., 2006. Hypergravity induces reorientation of cortical microtubules and modifies growth anisotropy in azuki bean epicotyls. Planta 224, 1485-1494.

Soga, K., Wakabayashi, K., Kamisaka, S., Hoson, T., 2007. Effects of hypergravity on expression of XTH genes in azuki bean epicotyls. Physiol. Plant. 131, 332-340.

Stutte, G.W., Monje, O., Hatfield, R.D., Paul, A.-L., Ferl, R.J., Simone, C.G., 2006. Microgravity effects on leaf morphology, cell structure, carbon metabolism and mRNA expression of dwarf wheat. Planta 224, 1038-1049.

Tabuchi, A., Mori, H., Kamisaka, S., Hoson, T., 2001. A new type of endo-xyloglucan transferase devoted to xyloglucan hydrolysis in the cell wall of azuki bean epicotyls. Plant Cell Physiol. 42, 154-161.

Tamaoki, D., Karahara, I., Nishiuchi, T., Oliveira S.D., Schreiber, L., Wakasugi, T., Yamada, K., Yamaguchi, K., Kamisaka, S., 2009. Transcriptome profiling in Arabidopsis inflorescence stems under hypergravity in terms of cell walls and plant hormones. Adv. Space Res. 44, 245-253.

Tamaoki, D., Karahara, I., Nishiuchi, T., Wakasugi, T., Yamada, K., Kamisaka, S., 2011. Involvement of auxin dynamics in hypergravity-induced promotion of lignin-related gene expression in Arabidopsis inflorescence stems. J. Exp. Bot. 62, 5463-5469.

Tamaoki, D., Karahara, I., Schreiber, L., Wakasugi, T., Yamada, K., Kamisaka, S., 2006. Effects of hypergravity conditions on elongation growth and lignin formation in the inflorescence stem of Arabidopsis thaliana. J. Plant Res. 119, 79-84.

Tan, K.S., Hoson, T., Masuda, Y., Kamisaka, S., 1991. Correlation between cell wall extensibility and the content of diferulic and ferulic acids in cell walls of Oryza sativa coleoptiles grown under water and in air. Physiol. Plant. 83, 397-403.

Tasaka, M., Kato, T., Fukaki, H., 2001. Genetic regulation of gravitropism in higher plants. Int. Rev. Cytol. 206, 135-154.

Timell, T.E., 1986. Compression Wood in Gymnosperms, Springer-Verlag, Heidelberg. 
Verhertbruggen, Y., Marcus, S.E., Chen, J., Knox, J.P., 2013. Cell wall pectic arabinans influence the mechanical properties of Arabidopsis thaliana inflorescence stems and their response to mechanical stress. Plant Cell Physiol. 54, 1278-1288.

Volkmann, D., Baluška, F., 2006. Gravity: one of the driving forces for evolution. Protoplasma, 229, $143-148$.

Wakabayashi, K., Nakano, S., Soga, K., Hoson, T., 2009. Cell wall-bound peroxidase activity and lignin formation in azuki bean epicotyls grown under hypergravity conditions. J. Plant Physiol. 166, 947-954.

Wakabayashi, K., Soga, K., Hoson, T., 2012. Phenylalanine ammonia-lyase and cell wall peroxidase are cooperatively involved in the extensive formation of ferulate network in cell walls of developing rice shoots. J. Plant Physiol. 169, 262-267.

Wakabayashi, K., Soga, K., Kamisaka, S., Hoson, T., 2005a. Increase in the level of arabinoxylan-hydroxycinnamate network in cell walls of wheat coleoptiles grown under continuous hypergravity conditions. Physiol. Plant. 125, 127-134.

Wakabayashi, K., Soga, K., Kamisaka, S., Hoson, T., 2005b. Changes in levels of cell wall constituents in wheat seedlings grown under continuous hypergravity conditions. Adv. Space Res. 36, 1292-1297.

Yoshida, K., Sakamoto, S., Kawai, T., Kobayashi, Y., Sato, K., Ichinose, Y., Yaoi, K., Akiyoshi-Endo, M., Sato, H., Takamizo, T., Ohme-Takagi, M., Mitsuda, N., 2013. Engineering the Oryza sativa cell wall with rice NAC transcription factors regulating secondary wall formation. Front. Plant Sci. 4, 383.

Yoshioka, R., Soga, K., Wakabayashi, K., Takeba, G., Hoson, T., 2003. Hypergravity-induced changes in gene expression in Arabidopsis hypocotyls. Adv. Space Res. 31, 2187-2193. 